\title{
MULHERES DEIXAM TRAÇOS NAS ÁGUAS?
}

DO WOMEN LEAVE TRACES IN THE OCEAN?

\author{
Alcione Corrêa Alves ${ }^{1}$
}

Resumo: Este artigo, mediante análise do romance Adèle et la pacotilleuse, de Raphaël Confiant, visa a examinar a centralidade da memória às construções identitárias da protagonista Céline Alvarez Bàà. Como aporte teórico à compreensão das construções identitárias no romance de Confiant, recorrese fundamentalmente ao conceito de memória, apropriado de Paul Ricoeur (2006), e à noção de lugar, conforme Édouard Glissant (1996), a fim de dar conta da relação entre a globalidade e a localidade, "telle qu'on puisse, sans défaire le lieu, sans diluer le lieu, l'ouvrir". Como hipótese de trabalho, considera-se que, enquanto Céline privilegiaria o legado materno resolvendo suas construções identitárias em termos de deslocamentos, talvez Bàà enuncie uma pergunta que, não necessariamente, se satisfaça desta maneira.

Palavras-chave: Construções identitárias afro-caribenhas; Memória; Deslocamento; Lugar de enunciação

\begin{abstract}
This article, by analyzing Raphaël Confiant's novel Adèle et la pacotilleuse, aims to examine the centrality of memory to identity constructions of the protagonist Céline Alvarez Bàà. As a theoretical contribution to understanding identity constructions in Confiant's novel, this article uses basically the concept of memory according to Paul Ricoeur (2006); and the notion of place according to ,Edouard Glissant (1996) to account for relationship between the global and the local, "telle qu'on puisse, sans défaire le lieu, sans diluer le lieu, l'ouvrir". As a hypothesis, it is considered that, while Céline would rather maternal legacy solving their identity constructions by means of displacements, perhaps Bàà sets out a question not necessarily be satisfied in this way.
\end{abstract}

Keywords: Afrocaribbean identity constructions; Memory; Displacement; Locus of enunciation

A Rita Terezinha Schmidt

1 Professor Doutor da Universidade Federal do Piauí: alcione@ufpi.edu.br

2 "de tal modo que seja possível, sem desfazer o lugar, sem dilui-lo, abri-lo" (tradução minha) 
Este artigo propõe uma análise do romance Adèle et la pacotilleuse, de Raphaël Confiant, com vistas a examinar a centralidade da memória às construções identitárias afroamericanas. Para tanto, o recorte de análise centra-se na protagonista Céline Alvarez Bàà e, mais precisamente, na observação dos legados de sua mãe, a andaluza Carmen, assim como de seu pai, o guineense Bàà. Como aporte teórico à compreensão das construções identitárias no romance de Confiant, recorre-se a uma abordagem que se apropria, fundamentalmente, do conceito de memória, a partir do artigo "La mémoire saisie par l'histoire", de Paul Ricoeur (2006), e da noção de lugar, conforme definida por Édouard Glissant no primeiro capítulo de Introduction à une poétique du Divers (1996); ambos aportes visam a compreender as construções identitárias de Céline observando a relação entre a globalidade e a localidade, "telle qu' on puisse, sans défaire le lieu, sans diluer le lieu, l'ouvrir" (1996, p. 31). Como hipótese de trabalho, considera-se que, enquanto Céline privilegiaria o legado materno resolvendo suas construções identitárias em termos de deslocamentos, seja no aprendizado e prática da pacotillage enquanto profissão eminentemente feminina, seja em suas experiências vividas nas diferentes ilhas do Mar do Caribe, talvez o legado de seu pai Bàà, julgado do ponto de vista de sua relação com Carmen, enuncie a Céline uma pergunta que, não necessariamente, se satisfaça em termos de deslocamento, exigindo um paradigma glocal a suas construções identitárias.

\section{Da memória}

Paul Ricoeur, no número 46 da Revista de Letras, publica um artigo intitulado "La mémoire saisie par l'histoire" no qual, esclarecendo dúvidas e objeções a sua noção de dévoir de mémoire, experimenta uma redefinição da relação entre memória e história ou, mais precisamente, "mémoire et histoire s'enroulent l'une sur l'autre, produisant alors in fine, comme une énigme terminale, le devoir de mémoire" (RICOEUR, 2006, p. 246)33. Note-se para os devidos fins que o contexto do artigo de Ricoeur remete à publicação, em 2000, de La mémoire, l'histoire et l'oubli, obra que, optando por uma definição linear de ambos os conceitos, se mostrou vulnerável às críticas ora respondidas e redefinidas no artigo em questão. Disto decorre uma abordagem da memória, em Ricoeur, que se mostra assaz frutífera a

3 "memória e história se enredam uma na outra, produzindo a partir daí, in fine, como um enigma terminal, o dever da memória" (tradução minha)

Organon, Porto Alegre, v. 29, n. 57, p. 77-98, jul/dez. 2014. 
uma apropriação pelo campo dos Estudos Literários e, neste caso, a um estudo das literaturas afro-americanas nas quais a memória das violências da Diáspora e do Tráfico tendem a ocupar, amiúde, posição central em suas construções identitárias.

Em Por uma estética dos vestígios memoriais, Zilá Bernd (2013) recorre ao referido texto de Ricoeur para analisar, em um exame da literatura contemporânea das Américas à luz da noção norteadora de vestígios, o problema da memória enquanto representação do passado na literatura:

Com relação à difícil questão da representação do passado, Ricoeur cita a bela metáfora da marca deixada por um timbre de cera quente: a marca está presente, mas o impacto do timbre sobre a cera já é passado. Essa ausência gera fronteiras porosas entre memória e imaginação. Com a distância temporal, cria-se o enigma de que o passado está presente na imagem como signo de ausência. Será essa ausência que a memória irá se esforçar por trazer à tona. (BERND, 2013, p. 34)

A metáfora do timbre de cera recupera uma tradição que, ao menos desde Teeteto (191c-196c), discute o valor cognitivo da memória não apenas enquanto recordação ou mesmo reevocação mas, igualmente, seu valor gnoseológico, de produção de conhecimento: em Platão, o bloco de cera visa a compreender a persistência das percepções na memória e nos pensamentos, além de situar a memória ao lado dos conteúdos que se sabe e que se percebe; analogamente, quando Bernd afirma que, malgrado não haja mais o impacto ou mesmo o fator impactante do timbre sobre a cera, persiste a marca, de tal afirmação se pode deduzir a reatualização do impacto vivido, das condições sob as quais o passado pode se reatualizar e significar no presente, àqueles que (apesar do impacto see passado), têm presente a marca.

Cumpre ressaltar, neste ponto, o quanto uma apropriação do modelo platônico do pedaço de cera, efetuada por Ricoeur e salientada por Bernd, se apresenta sobremaneira frutífera se operacionalizada a um estudo das literaturas afro-americanas, à medida que se nelas evidencie o trauma (WALTER, 2011) decorrente do Tráfico como elemento recorrente e, mesmo, como categoria de análise, em um exercício científico no qual se buscaria, na cera destas literaturas, como se mostram impressas as marcas e como os diferentes textos literários afro-americanos as (res)significam ${ }^{4}$.

4 Tal como Bernd leva a termo na mesma obra, no capítulo "Poética afro-brasileira: resgatando a memória transatlântica" (2013, p. 61-76).

Organon, Porto Alegre, v. 29, n. 57, p. 77-98, jul/dez. 2014. 
Tal exercício se intensifica quando se observa, também, como Ricoeur apropria a noção de reconnaissance em sua leitura de Henri Bergson e, em decorrência disso, de como memória e história se bifurcam a partir de tal noção (RICOEUR, 2006, p. 246).

Contudo, com o fim de operar de modo mais abrangente tal apropriação, faz-se mister levar em conta o lugar de enunciação dos sujeitos afroamericanos, cujos discursos e corpos sempre trazem a marca ${ }^{5}$ : não se pode aceitar que "a marca está presente, mas o impacto do timbre sobre a cera já é passado" aceitando este uso de mas pois, desde um lugar de enunciação dos sujeitos negros descendentes de processos de escravização, ainda que o impacto seja fisiologicamente/clinicamente "passado", a representação desse passado, à luz do "retour du passé que nous appelons reconnaissance" (RICOEUR, 2006, p. 246), advoga precisamente que "a marca está presente". Mesmo em sujeitos negros contemporâneos, hoje inseridos e integrados em ambientes democráticos e de garantias constitucionais universais, as práticas socialmente convencionadas de segregação e intolerância rememoram a estes sujeitos, cotidianamente, que "a marca está presente". Mesmo que nenhuma negra(o) estejam formalmente escravizadas(os), rememora-se cotidianamente a sujeitos negros seu suposto lugar ${ }^{6}$, como forma de assinalar que "a marca está presente", seja em seu fenótipo, seja em quaisquer signos que tracem uma aproximação de qualquer natureza com a ideia comum de culturas africanas subsaarianas ${ }^{7}$. Uma leitura da metáfora de Ricoeur, desde um lugar afro-americano, e com vistas à operacionalização de um conceito de memória para compreensão de literaturas afro-americanas (compreendida, aqui, a literatura afrobrasileira), aceitaria os termos propostos, à condição de substituída sua ordem: "o impacto do timbre sobre a cera já é passado, mas a marca está presente". Como em Justine que, malgrado a fé inabalável da protagonista

5 O uso de sempre, em itálico, se justifica pelo compromisso teórico com a introdução de Cultura e imperialismo onde Edward Said (1995) advoga, como premissa de sua obra, a regularidade (quiçá a necessidade) da resistência das populações colonizadas por Inglaterra e França, entre os séculos XVIII e XIX - resistência não apenas observável nas literaturas destas comunidades mas, igualmente, nos próprios cânones literários inglês e francês do período, tema de estudo da obra.

6 E, por conseguinte, seus lugares interditos, caso se aceite que, conforme Édouard Glissant (1997), a definição do Ser implicaria não apenas definir o que é mas, também (quiçá sobretudo), definir o que não é. Do que decorreria uma definição do Ser operando por exclusão daquilo que não corresponde. Tal constatação de Glissant se estabelece em diálogo com a metafísica da presença, conforme Jacques Derrida (1967), explicitada por Jonathan Culler (1985) .

7 Como se o atual cenário político-cultural brasileiro operasse uma atualização, radical e tácita, do princípio one drop rule. Fundamos-nos em outras matrizes jurídicas, mas a fundamentação de nossos racismos adota, em suas últimas consequências, um princípio análogo como justificativa de supressão da diferença associada ao fenótipo negróide.

Organon, Porto Alegre, v. 29, n. 57, p. 77-98, jul/dez. 2014. 
e suas experiências, padece precisamente porque "a marca está presente": como lhe advogar o passado do timbre, da dor (inclusive física) rediviva a cada olhar sobre a marca?

Por fim, e de modo central à leitura de Adèle et la pacotilleuse ora proposta, afirmar que "o passado está presente na imagem como signo de ausência" assinala, de modo bastante instigante, a ambivalência na tradução de trace em português brasileiro. Se "a marca está presente", trata-se de rastros, vestígios, pistas na cera/pele dos sujeitos negros escravizados e seus descendentes; contudo, sob qual superfície se marca, se mensura "o impacto do timbre sobre a cera"? Quando Bàà, pai de Céline, relata-lhe as mortes de negros escravizados durante as travessias dos negreiros (a sua, inclusive), como poderia marcar suas memórias sobre as águas? De modo análogo, como os cadáveres das mulheres repousando no fundo do Atlântico em Humus, de Fabienne Kanor (2007); e como os cadáveres daquelas(es) que não completaram a travessia descrita por Preta Suzana em Úrsula (2004), de Maria Firmina dos Reis; como tantos esquifes negros representariam, a contento, "o impacto do timbre sobre a cera"? E, mais radicalmente, se pensamos no esforço narrativo de Humus em representar a voz das onze mulheres em busca de sua liberdade na morte; ou no esforço análogo para viabilizar a voz de Tituba em Moi Tituba sorcière..., contrariamente a quase toda tradição ficcional em torno dos eventos de Salém; sob tais condições, se pode investigar a hipótese de que certos sujeitos não gozam da prerrogativa da fala sobre a marca, embora a tragam na cera. Sua fala "está presente na imagem como signo de ausência".

Céline, desde o princípio do romance de Raphaël Confiant, entrega-se à empresa de falar sua marca.

\section{Do lugar}

L'important aujourd'hui est précisément de savoir discuter d'une poétique de la Relation telle qu'on puisse, sans défaire le lieu, sans diluer le lieu, louvrir. Est-ce que nous avons les moyens de le faire? Est-ce que c'est réalisable par l'homme, par le genre humain, par lêtre humain? Ou est-ce que nous devons considérer une fois pour toutes que pour préserver le lieu il nous faut préserver l'exclusif du lieu? Je n'ai pas nié qu'il y a là une question (GLISSANT, 1996, p. 29-30)

O importante, no momento atual, é, precisamente, saber discutir uma poética da Relação de tal modo que seja possível, sem desfazer o lugar, sem dilui-lo, abri-lo. Dispomos dos meios para 
fazê-lo? [Tal tarefa] é realizável pelo homem, pelo gênero humano, pelo ser humano? Ou devemos considerar, de uma vez por todas que, para preservar o lugar, é necessário preservar a exclusividade do lugar? Não neguei que, aí, repousa um problema. (tradução minha)

Em Introduction à une poétique du Divers, Édouard Glissant reconhece a instabilidade e a provisoriedade das identidades em um mundo contemporâneo, sob o signo de uma poética da Relação; tais identidades se mostram, no pensamento glissantiano, coerentes à imprevisibilidade e à provisoriedade caras à crioulização, percebendo uma possibilidade, não negligenciável, de inexequibilidade das trocas culturais tal como preconizadas em um modelo rizomático. Em um contexto contemporâneo de crise econômica assolando parte do Ocidente, notadamente parte da comunidade europeia, formas superadas de nacionalismos readquirem fôlego nos debates político-culturais: cada novo muro reivindicando fronteiras nacionais e segregação étnica ou religiosa, como solução aos problemas econômicos, recoloca diuturnamente, com novos dados, o problema da diferença e seu tratamento mediante sua supressão.

A atual crise econômica como fator de deflagração de crises identitárias aparentemente superadas no Ocidente tem, como fundamento, a exacerbação de uma ordem econômica capaz, por vezes, de se tornar homóloga a explicações jurídicas, filosóficas e teológicas do mundo. A esse respeito, Roland Walter (2008) salienta que os conceitos para se pensar as construções identitárias contemporâneas necessitam também tratar dos impasses inerentes à globalização:

A globalização [...] introduz as noções de desterritorialização, dispersão e hibridismo dentro de uma cultura global de certa maneira sem raízes e contextos fixos. Essa disseminação global da economia e da cultura baseada num paradigma liberal, porém, tem que ser vista junto com as raízes culturais locais baseadas num paradigma tradicional (e em geral mais conservador). Em outras palavras, a globalização alimenta-se da tensão entre coesão e dispersão, raízes fixas e rotas rizomáticas, homogeneização e heterogeneização, fronteiras abrindo para seus espaços fronteiriços e fronteiras fechadas (WALTER, 2008, p. 38).

Neste sentido, os diversos conceitos possíveis de globalização, do ponto de vista das formações identitárias contemporâneas, "introduz[em] as noções de desterritorialização, dispersão e hibridismo dentro de uma 
cultura global", de modo a fornecer um quadro mais amplo que críticas erigidas apenas, ou predominantemente, de um lugar econômico. $\mathrm{O}$ âmbito de "uma cultura global" proporciona, ao campo dos Estudos Culturais, ferramentas críticas tais como os conceitos de desterritorialização e hibridismo, permitindo a compreensão de identidades em trânsito, "de certa maneira sem raízes e contextos fixos". Prosseguindo sua explanação, Walter recorre à conjunção adversativa porém para ressaltar dois aspectos complementares à ideia de globalização, a saber, "uma cultura global de certa maneira sem raízes e contextos fixos" e, sem contradição de termos, "as raízes culturais locais baseadas num paradigma tradicional (e em geral mais conservador)", ao que a complementaridade é intensificada com uma "disseminação global da economia e da cultura baseada num paradigma liberal”. Ao recurso à conjunção aditiva $e$ para tratar da disseminação de duas dimensões distintas (a economia e a cultura) em um contexto global, cabe recorrer, de modo complementar, a Pascal Gin (2008):

Effectivement, la mobilité humaine des flux migratoires et des imaginaires diasporiques ne recoupe pas nécessairement la mobilité systémique des réseaux économiques. Pareillement, la mobilité technologico-médiatique de la macrosphère de l'information et du transfert de données ne témoigne aucunement de la complexité des mobilités propres aux pratiques culturelles, avec tout ce que celles-ci comportent d'adaptation, de localisation, d'emprunt et de transformation. Cette diversité des phénomènes explique et motive lécart des analyses qu'en propose aujourd'hui le domaine élargi des sciences humaines. (GIN, 2008, p. 74)

Efetivamente, a mobilidade humana dos fluxos migratórios e dos imaginários diaspóricos não necessariamente recobre a mobilidade sistemática das redes econômicas. Paralelamente, a mobilidade tecnológico-midiática da macrosfera da informação e da transferência de dados não oferece testemunho, de modo algum, da complexidade das mobilidades próprias às práticas culturais, com tudo o que comportam de adaptação, localização, empréstimos e transformação. Esta diversidade de fenômenos explica e motiva a limitação de análises hoje propostas, no domínio das ciências humanas (tradução minha)

A distinção entre as diferentes mobilidades das redes econômicas proporciona um elemento adicional à compreensão da globalização, em Walter: "uma cultura global de certa maneira sem raízes e contextos fixos" e, simultaneamente e sem contradição de termos, "as raízes culturais locais baseadas num paradigma tradicional (e em geral mais conservador)". Es- 
tabelece-se, destarte, o diálogo direto entre o texto de Walter e a pergunta de Glissant: sob quais condições é possível "discuter d'une poétique de la Relation telle qu'on puisse, sans défaire le lieu, sans diluer le lieu, l'ouvrir"? (GLISSANT, 1996, p. 30)

Ao formular a pergunta sobre a exequibilidade de uma poética da Relação seja como compreensão das formações identitárias, seja como projeto coletivo a um contexto global, Glissant não visa a descartar as possibilidades de identidades rizomáticas, mas a preconizar uma vigilância epistemológica no tocante aos debates, incessantes, sobre o conceito de identidade - vigilância igualmente preconizada por Walter (2009, p. 94) e por Gin, ao ressaltar "l'expérience de la mobilité" (2008, p. 73-74).

A epígrafe desta seção corresponde, no contexto mais amplo de Introduction à une poétique du Divers, à parte final do primeiro capítulo, intitulado "Créolisations dans la Caraïbe et les Amériques", na qual Glissant expôs a noção de crioulização e sua tese forte, a de que o mundo se criouliza. Tendo em vista que cada capítulo da obra se encerra com uma seção de questões, cumpre destacar que a primeira questão no primeiro capítulo, proposta a Glissant pelo ensaísta quebequense Robert Melançon, incide sobre a demonstração do conceito de crioulização enquanto processo:

[...] Et donc, est-ce qu'on peut redéfinir la créolisation comme un état de turbulence de systèmes qui sont mis en présence et est-ce qu'on n'est pas amené à penser qu'au bout d'une assez longue période de turbulences, il se produise fatalement une stase [...]? La céolisation du monde se produisant aujourd 'hui à un moment où la terre est enfin une, $n$ 'aboutira-t-elle pas à un état d'unification qui arrêterait complètement le movement, parce qu'il $\mathrm{n}^{\prime} \mathrm{y}$ aurait pas déléments extérieurs, déléments étrangers? (MELANÇON, apud GLISSANT, 1996, p. 26)

Portanto, pode-se redefinir a crioulização como um estado de turbulência de sistemas postas em presença e, deste modo, não seríamos conduzidos a pensar que, ao final de um período suficientemente longo de tais turbulências produzir-se-ia, fatalmente, uma estase [...]? A crioulização do mundo atualmente em curso, em um momento no qual a terra é, enfim, uma, não redundaria em um estado de unificação que cessaria completamente o movimento, visto que não haveria mais elementos exteriores, elementos estrangeiros? (tradução minha)

A questão formulada por Melançon indaga a possibilidade de uma estase, como ponto culminante dos processos globais de crioulização - para 
os quais se apresenta um campo semântico em que os processos consistem em turbulences e seus resultados são definidos pelos substantivos stase, pela expressão état d'unification, assim como pelo verbo arrêter.: à questão, nestes termos, subjaz um conceito de síntese que visa a definir as conclusões do processo de crioulização. Síntese, nesse aspecto, representa um conceito a delimitar uma certa concepção dos processos atinentes aos fenômenos culturais, de modo a determinar resultados e, em última instância, um quadro global de estabilização uma vez esgotadas as possibilidades aos "systèmes qui sont mis en présence".

A compreensão da crioulização, em Glissant, necessita da ideia de processo, graças a qual o autor pode descartar o risco de uma síntese final, homogeneizante, assim como uma hipotética estase das culturas em um contexto global. A consciência da crioulização é apresentada como um fator de reativação do processo, contra a estabilidade proposta pelo ser:

Maintenant, est-ce que ce processus - car la créolisation est un processus - parviendrait à un état, à une phase finale? Je ne le crois pas parce que c'est la conscience qui réactive le processus et c'est la non-science, la non-conscience, qui le stabiliserait en une identité définie (GLISSANT, 1996, p. 27)

Neste momento, esse processo - visto que a crioulização é um processo - não nos levaria a um estado, uma fase final? Não creio nisso porque a consciência reativa o processo e a não-ciência, a não-consciência, estabilizá-la-ia em uma identidade definida (tradução minha)

A consciência opera como elemento de crioulização, a serviço de seu caráter processual, consciência essa situada na base de uma permutação intelectual, espiritual e mental da época presente, de modo a impossibilitar o retorno à segurança proporcionada pela síntese e, em última instância, a quaisquer sistemas totalizantes de explicação do homem. Em tal quadro, encontrar-se-ia comprometida a pretensão do pensamento de sistema a explicações totalizantes e universais de formações culturais contemporâneas, ou a definições universais do homem e do mundo. A crioulização desestabilizaria definitivamente a segurança proporcionada pela síntese, malgrado permaneça subjacente a algumas de ferramentas críticas à compreensão das culturas. Conforme tal quadro teórico, o rizoma, na apropriação de Glissant, não consiste em um inverso dicotômico da raiz, ou Organon, Porto Alegre, v. 29, n. 57, p. 77-98, jul/dez. 2014. 
uma não-raiz: antes, o rizoma representa, enquanto distinção a serviço da compreensão de formações identitárias, "racine, mais allant à la rencontre d'autres racines" (Idem, p. 31).

\section{Dos traços}

São recorrentes, em Adèle et la pacotilleuse, eventos narrativos que em princípio constituiriam circunstâncias impeditivas a uma troca, a uma coabitação rizomática de diferentes identidades mas que, ao fim e ao cabo, oferecem circunstâncias renovadas a uma permanente negociação de modos, identidades possíveis ao espaço insular que se constroem e se remodelam mediante soluções provisórias, permanentemente renegociáveis. A essa característica determinante ao texto de Confiant, soma-se a profusão de eventos narrativos que suscitam o problema da compatibilidade entre apreciações globais e locais do arquipélago caribenho . .

Pode-se observar, por exemplo, a análise comparativa entre as representações do mar em Carmen e em Bàà, e do quanto tais representações convergem na construção identitária de Céline como mulher-em-exílio. Se o mar fora explicitado como um princípio de vida a Carmen, na forma de um cônjuge com que ela efetiva seu estar-no-mundo, o mar também opera como mediação dos termos da união entre ela e Bàà:

Mon vrai conjoint est et restera toujours le voyage, et il n'est pas question pour moi de m'installer dans une case pour cuisinelaver-repasser pour une fainéant avec deux graines entre les jambes. Cette vie-là n'est pas faite pour moi. Je suis pacotilleuse et $\mathrm{j}$ 'ai des pratiques qui comptent sur moi dans toutes les îles et sur la terre ferme (CONFIANT, 2007, p. 75-76)

Carmen opera em uma dicotomia entre a mobilidade e a fixidez, esta última representada em seu discurso por um modelo de sujeição da mulher às lides domésticas (cuisiner-laver-repasser), de tal modo que a mobilidade propicia a liberdade a suas identidades enquanto caribenha e enquanto mulher. Por isso, a atividade da pacotillage é feminina, por excelência, definição de gênero preconizada, inclusive, nos dez mandamentos do código de conduta da profissão (p. 160-161). Por isso, se estabelece a oposição entre as pacotilleuses e as femmes-matador (p. 103-104), estas igualmente modelos a ser recusados enquanto índice de fixidez: em sua atividade de explicação a uma Adèle Hugo tomada como filha, Céline explicita os termos dos deslocamentos na natureza das pacotilleuses: 
Car, explique Céline Alvarez Bàà à une Adèle muette et figée, notre vie à nous, les pacotilleuses, est um incéssant aller-venir. Nous sommes pires que des fourmis-manioc. Nous $n$ 'avons pas fait une halte en quelque endroit qu'il nous faut déjà songer à repartir. Nous n'avons pas de temps pour la rigoladerie. La franche vérité, ma petite Adèle, c'est que nous ne sommes heureuses, vraiment heureuses, qu'en pleine mer (Ibid., p. 103)

Assim como Carmen situara o mar como instância inalienável, quando da narração de sua prisão na ilha de Saba (p. 73), repassando a tradição herdada de sua mãe a sua filha Céline, esta, na página 103, efetua o gesto análogo de repassar a tradição herdada de Carmen àquela chegada no momento em que "Il y avait beau temps que je rêvais d'avoir un enfant à moi" (p. 17). O uso do qualificativo heureuses, intensificado pelo advérbio de modo vraiment, confere uma dimensão ética ao deslocamento de Céline, uma vez que a errância pelo Mar das Antilhas, bem como as duas viagens empreendidas à França, se tornam instâncias de felicidade a mulheres que, no exercício de sua profissão, são "pires que de fourmis-manioc", o que remete à análise de Nestor García Canclini da instalação Wandering position, na qual o artista plástico Yakinori Yanagi faz com que formigas perambulem em um mapa-múndi feito de areia colorida, e onde a cada país corresponde uma cor: "a perambulação das formigas pela areia vai mesclando as cores-bandeiras-nações até provocar a dissolução de limites e marcas identitárias. Há, nessa instalação, uma inegável crítica ao imobilismo decorrente daquilo que a globalização possui de hegemônico e homogeneizador" (GAGLIETTI; BARBOSA, 2007, p. 5-6). Na análise do romance de Confiant, a imagem das fourmi-manioc associada às pacotilleuses ganha força interpretativa quando se atenta a três aspectos.

Em primeiro lugar, a perambulação das formigas redesenha construções identitárias inicialmente nacionais mas que se crioulizam por conta da dissolução de fronteiras. Isso se dá, no caso do romance, mediante o exercício profissional das pacotilleuses em sua perambulação; à dissolução de identidades homogêneas, cada uma contribui com sua "histoire faite de drivailles, d'errances" (p. 14), onde cada novo partir-revenir dissolve, decisivamente, a configuração das fronteiras no mapa caribenho amiúde projetado segundo uma cartografia ocidental, exógena. Destarte, a perambulação das pacotilleuses e, por extensão, dos sujeitos caribenhos não apenas descentra a cartografia ocidental como, em si mesmas, elaboram seus próprios mapas - o que autoriza Céline a incluir "un vaste empan de terre ferme" (p. 83) em seu mapa do Caribe.

Organon, Porto Alegre, v. 29, n. 57, p. 77-98, jul/dez. 2014. 
Em segundo lugar, a perambulação das formigas se dá, contrariamente à instalação de Yanagi, em meio aquoso, implicando que as fronteiras estipuladas por uma cartografia ocidental operam uma divisão do Mar que não corresponde, nem subsume a compreensão do espaço caribenho operada pelos sujeitos que nele habitam: as construções identitárias não são definidas conforme as cores atribuídas às águas pelos mapas ocidentais, mas pela perambulação das formigas em seu aller-venir pelas águas de um mar que, segundo Glissant, difrata (1996, p. 14-15). Ademais, é preciso sublinhar o comportamento do traço que, no mar, se apaga: a perambulação das formigas revolve as águas, redesenhando as cartografias (as águas, de cores diversas, se misturam) e os próprios traços que, quando revolvidos pelo trânsito dos sujeitos nas águas, abrem a possibilidade de novos significados.

Em terceiro lugar, a apropriação da instalação de Yanagi exige um dado complementar à perambulação: formigas ocupam a terra, simultaneamente, perambulando $e$ cavando, de modo a construir suas comunidades subterrâneas. O uso da conjunção $e$ resgata a proposta glissantiana do rizoma como "la racine qui s'étend à la rencontre d'autres racines"8 (Idem, p. 59), de modo a partilhar a mesma terra sem, necessariamente, a exclusão de outros sujeitos ou comunidades.

\section{Do deslocamento materno e da fixidez paterna}

Sobre o primeiro encontro dos pais de Céline, é preciso incidir sobre uma observação fundamental, a saber, o caráter de "couple dépareillé" da união entre Carmen e Bàà: "Parfois, elle lui intimait l'ordre de cesser de baliverner. Ses histoires de vieux Nègre n'intéresserait plus personne! Jamais couple ne fut plus dépareillé. Je ne $m$ 'en suis rendu compte que longtemps, très longtemps, après la mort de mon père" (CONFIANT, 2007, p. 68). A percepção do dépareillement do casal só pode se tornar possível a Céline após sua compreensão do exílio como força criadora para Carmen e, em segundo lugar, somente após sua compreensão de que há mais de um conceito de exílio. Não por acaso, este é o momento da narrativa em que Céline explicará aos leitores sua concepção de exílio herdada de Carmen para, a partir dela, demonstrar como o exílio é percebido por Adèle Hugo, em uma dicotomia segundo a qual, aos sujeitos arquipélicos, "1'exil nous a créés" (operando a silepse de nous) ao passo que aos franceses como

8 "raiz que se estende ao encontro de outras raízes" (tradução minha)

Organon, Porto Alegre, v. 29, n. 57, p. 77-98, jul/dez. 2014. 
Adèle, o exílio é percebido como "une épreuve. Comme um déchirement" (levando-se em conta, simultaneamente, o exílio de Adèle e, contemporâneo a ele, o exílio político de Hugo). Resgatando-se a distinção entre os pensamentos de traço e de sistema, é possível propor que ao primeiro, na condição de pensamento arquipélico, corresponde uma dimensão criadora do exílio, na qual a crioulização pode ser vivida como processo de trocas culturais, prescindindo da primazia de uma pátria-mãe em relação a outras possibilidades da totalidade-mundo. Sob tais condições, Carmen demonstra a Céline, como parte do ofício de pacotilleuse e como concepção de mundo, que "partir-revenir est notre destin" (p. 39) e, não por acaso, o dado de que Céline herda a profissão de Carmen, somado ao dado de que, em sua narrativa de vida, falar da mãe implica amiúde falar do pai (p. 44), se mostram significativos à diegese.

A primazia da herança materna se situa na base da dificuldade de Céline em compreender a contribuição de Bàà em sua construção identitária, de modo a se apropriar adequadamente de sua herança ainda tributária da idéia do "couple dépareillé". Desenvolvendo a referida dificuldade, percebe-se esquematicamente ante o deslocamento da andaluza Carmen, a fixidez do trinidadiano Bàà, escravizado em uma fazenda de cana em Trinidad que, após a abolição da escravatura, permaneceu na condição de trabalhador na mesma fazenda:

Mon père usait son corps sur une vaste plantation de canne à sucre, dans l'intérieur de l'île de Trinidad, à une bonne trentaine de miles de la capitale où, avant cet instant fameux, il n'était jamais descendu. Du temps de l'esclavage, il coupait la canne et continua à le faire après l'abolition (Ibid., p. 69) ${ }^{9}$

Tanto a herança andaluza de Carmen (nascida em Santo Domingo) quanto a herança guineense de Bàà (nascido em Trinidad e Tobago) se mostram práticas desviantes ante a inviabilidade da genealogia aos sujeitos antilhanos ou, no dizer de Céline, a "nous les Amérindiens-Nègres-Blancs-Mulâtres-Chabins-Indiens-Chinois-Syriens de l'Archipel” (p. 67). Sob tais condições, a inviabilidade de uma genealogia conforme o mode-

9 A escolha de Bàà em permanecer na fazenda onde estivera escravizado, logo após a abolição, mostra-se afim à diegese de La panse du chacal, romance anterior de Confiant que retrata a chegada dos imigrantes indianos à Martinica em um contexto pós-abolicionista. Nessa obra, os indianos vêm precisamente para suprir a posição de braço trabalhador nos engenhos, ao lado dos negros que, ante a ausência de perspectivas nas cidades antilhanas, optaram por permanecer como empregados de seus antigos senhores. 
lo ocidental permite aos sujeitos afrocaribenhos tributários da diáspora negra a busca de heranças identitárias em outro lugar, simultaneamente exaurindo as possibilidades do traço (com a memória operando sobre o que nos vêm de África e de Europa, além de "d'autres terres aussi dont j'ai peine à prononcer les noms et à imaginer l'étendue") e incidindo sobre a força criadora do exílio enquanto "notre condition", "notre destin", "[ce qui] nous a créés".

Note-se, na narrativa de Céline, a presença de índices textuais que, desenhando o perfil de Bàà, visam a intensificar sua fixidez em comparação à mobilidade de Carmen e a sua própria. Para além do ambiente da plantação de cana, a fixação à terra se estabelece pelo afastamento do litoral da ilha ("à une bonne trentaine de miles de la capitale"), por jamais haver saído da fazenda ("il n'était jamais descendu [à la capitale]"), por sua condição de sujeito escravizado destoante da liberdade de Carmen e de Céline e, enfim, por sua decisão de permanecer trabalhando na fazenda, após a abolição ("du temps de l'esclavage, il coupait la canne et continua à le faire après"). Apesar de Céline reproduzir, entre aspas, a fala de um Bàà já liberto, é possível suscitar uma dúvida legítima sobre até que ponto ela compreende a decisão de seu pai ou, em contrapartida, interpreta-a como um índice de fixidez (sempre tomada em oposição à mobilidade de Carmen ${ }^{10}$ :

Nous n'avions plus de chaînes aux pieds et on ne nous fouettait plus, solliloquait-il, mais notre vie n'avait pas embelli pour autant. Chaque jour se répétait à l'identique. De beau matin, il fallait se rassembler dans la cour de la maison de celui que tout un chacun, par habitude, continuait à appeler le maître, et attendre les ordres d'un commandeur plus scélérat que la scélératesse elle-même (Ibid., p. 69)

Para além da intervenção de Céline na primeira linha da fala de Bàà, com vistas a caracterizá-la como um solilóquio (ao contrário de um ensinamento, de um saber), há outros elementos a demonstrar que a escravização cessara apenas formalmente, caso se tome em consideração as condições de vida possíveis aos negros libertos nas ilhas: a vida "n’avait pas embelli pour autant", a rotina dos dias de servidão "se répétait à l'identique" e, sobretudo, permanecem o mesmo mestre e a mesma relação deste com seus

$10 \mathrm{O}$ problema de uma mensuração da herança paterna na genealogia consiste no ponto de partida do problema desenvolvido em L'Africain, de Jean Marie Gustave Le Clézio (2008): o protagonista visa a empreender uma viagem à África em busca de suas origens maternas mas descobre que seu antepassado africano não é a mãe, mas o pai. 
outrora escravizados. As perspectivas de fixidez de Bàà apenas poderão ser descentradas quando de seu primeiro contato com o mar e, em decorrência dele, com Carmen. Após seu primeiro contato com o mar, percebe-se um deslocamento, sob a forma de mudança de profissão: de trabalhador do eito, Bàà passa a responsável pelos cuidados dos cavalos:

Sa nouvelle tache était moins rude. Habillé de propre, il ne lui incombait que de bouchonner les chevaux du planteur et de faire reluire les cuivres de son tilbury. La route, pourtant défoncée, entre Palm Plantation et la côte, lui était une manière de paradis en comparaison du mitan de champs de canne à sucre ou la négraille bourriquait, sous l'accablant soleil du carême. Bàà ne cessait jamais de cracher au visage de la mer pendant les quinze années d'exercice de sa nouvelle profession. Jamais (Ibid., p. 70)

Primeiramente, deve-se ressaltar o deslocamento como instância transgressora uma vez que, por intermédio das viagens a cavalo até a cidade "habillé de propre"11 e do contato com o mar, criam-se as condições para que Bàà transforme sua apreciação do arquipélago, bem como para que Céline compreenda as decisões possíveis a seu pai dentro de um quadro pós-abolicionista. Enfatizar a dimensão transgressora dos deslocamentos de Bàà permite analisá-lo comparativamente ao Makandal de El reino de este mundo (CARPENTIER, s.d.) que, do fato de gozar a possibilidade do deslocamento graças a suas limitações físicas (teve o braço amputado pelo moedor de cana, o que lhe levou a ser designado ao pastoreio), fora considerado inofensivo por sua deficiência, e dada a natureza de sua nova função, constroi novas práticas transgressoras a partir das possibilidades apresentadas. Contudo, diferentemente da transgressão coletiva de Makandal, Bàà opera uma transgressão para si.

Em segundo lugar, percebem-se dois aspectos limitadores à transgressão de Bàà:

11 Do ponto de vista de um ex-escravizado, é fundamental estar "habillé de propre" ou, mais especificamente, se distinguir de um nèg-sans-souliers, como a Esternome fora possível se distinguir dos negros da feira dominical, no subcapítulo "Nèg-sans-souliers" de Texaco (CHAMOISEAU, 1992, p. 78-82). No modelo brasileiro de escravização, assim como em outras comunidades americanas, a ausência de sapatos demarcava, socialmente, a condição cativa do negro, ao que a concessão de sapatos, por parte dos senhores, amiúde representava um gesto de alforria ao escravizado, como ao personagem Valentim, interpretado por Antônio Pitanga no filme Mauá - o imperador e o rei, de Sérgio Rezende (1999). 
- uma vez se tornado um trabalhador cujo regime diferia daquele da plantação (para o que Céline usa o termo "négraille"), o personagem não percebe claramente a hierarquia estabelecida claramente em prejuízo dos os trabalhadores da cana, em relação aos demais trabalhadores da fazenda;

- e, em segundo lugar, a instância transgressora do deslocamento de Bàà, rumo a uma nova função na fazenda e rumo ao mar, oferece o risco de olvidá-lo de sua condição ainda de dominado, embora liberto visto que, segundo ele próprio, permanece a figura do mestre.

Do segundo aspecto decorreria uma fixidez, representada na manutenção do regime econômico da monocultura, que portaria uma máscara, qual seja, o deslocamento de Bàà proporcionado por sua nova função (representada pela abolição como liberdade aparente); essa fixidez será radicalizada pela distinção estabelecida entre Bàà como trabalhadorem-deslocamento em comparação à négraille que permanece no eito. Sem reconhecer que uma distinção de tal natureza opera apenas na mente daqueles submissos ao regime da fazenda, corre-se o risco de não perceber o deslocamento de uns em detrimento da fixidez de outros. Aqui, caso os sujeitos-em-deslocamento não tomem em consideração a provisoriedade de suas práticas desviantes, comprometem seu potencial transgressor ${ }^{12}$.

Convém destacar um último ponto de análise comparativa entre Carmen e Bàà, do ponto de vista do mar. Se, para ela, o mar surge como princípio criador, como elemento que propicia as trocas, os deslocamentos, para Bàà, ao contrário, o Oceano Atlântico representa um cemitério, em um esquema aparentemente dicotômico no qual o mesmo mar, que é vida para Carmen, seria morte para Bàà:

L'Atlantique est le plus grand cimetière du monde, déclaraitil à qui voulait entendre. Si on était encore dans les premiers temps, à l'époque ou le Nègre n'avait pas encore été tout-à-faitement souillé par les turpitudes de l'Europe, eh ben j'aurais

$12 \mathrm{O}$ que estabelece uma distinção fundamental entre Bàà e Makandal que, sem esquecer a provisoriedade de sua fuga da fazenda como prática desviante, possibilita a esta um papel ativo na sublevação dos sujeitos escravizados, mediante o envenenamento de seus senhores. Do ponto de vista do deslocamento, Bàà pode ser comparado não apenas a Makandal em El reino de este mundo mas, igualmente, a Ariel, o espírito mulato de Une tempête que, graças a sua fidelidade a Próspero, bem como a sua condição de intelectual, tem acesso aos livros secretos do mestre, interditados a Caliban : tal como a deficiência física de Makandal, a fidelidade incondicional de Ariel torna-o inofensivo aos olhos de seu mestre, permitindo o espaço de busca de liberdade em outro lugar que não o enfrentamento no campo da linguagem, como o faz Caliban.

Organon, Porto Alegre, v. 29, n. 57, p. 77-98, jul/dez. 2014. 
tué mon corps sur-le-champ. Oui, j'aurais avalé ma langue à l'envers, flap! Ou bien je me serais pendu à la branche la plus solide d'un pied de lépini. Et là, mon ame aurait retraversé les flots en un battement d'yeux pour rejoinder ma Guinée natale (CONFIANT, 2007, p. 68)

O mar simboliza a morte, para Bàà, por remeter não às trocas entre as comunidades arquipélicas, como no caso de Carmen, mas por evocar o ventre do navio negreiro, e todos aqueles africanos escravizados que, por morte, doença, insubordinação, eram arremessados ao mar durante as travessias - ou se arremessavam, politicamente, como as narradoras de Humus . No fundo do mar, repousam depositados os corpos dos mortos nos navios, desenhando uma trilha de esqueletos no trajeto equivalente às rotas. Enquanto para Carmen, o mar representa o lugar onde se dão as crioulizações linguísticas de tal modo que, com exceção do dinamarquês, ela fala todas as demais, para Bàà o mar é o ventre do navio no qual se distribuem tantas línguas quanto sujeitos cativos, com vistas a inviabilizar a comunicação. Para Bàà, o mar é o lugar onde se deve calar.

Para além de uma dicotomia entre o mar da vida e o mar da morte, o conceito de mar intervalar, proposto pela escritora canadense Dionne Brand, ajuda a compreender o debate entre Carmen e Bàà, à medida que o mar passa a ser tomado o mar como "essa porta de não-volta" (BRAND, apud SEIDEL, 2009, p.9). Note-se, a este respeito, que Bàà cogitara o suicídio, dentre outras razões porque, com a morte, ser-lhe-ia possível retornar à terra natal, refazendo a travessia - atravessando o cemitério. Para evitar o que Seidel denomina "o risco da esquizofrenia cultural" na forma de um retorno a um paradigma racial, a dimensão do mar intervalar pode ser enriquecida através não de uma pulsão de retorno como a alimentada por Bàà, mas de uma solução como a das personagens de Humus ou do Caliban do poeta jamaicano Kamau Brathwaite, para os quais a travessia, mais do que entre-lugar, consiste em um lugar gnoseológico propriamente dito: é no ventre do navio negreiro que começam a ser gestadas as futuras línguas crioulas, que começam a ser gestadas as insurreições ${ }^{13}$.

13 Além do poema "Caliban", de Brathwaite, outro exemplo do valor gnoseológico da travessia consiste no documentário Atlântico negro, no qual são analisados dois eixos comparativos. Em um deles, são comparados instrumentos musicais e outros utensílios entre duas comunidades negras, uma no Maranhão e outra, no Benin, no que se ressalta suas continuidades, partindo do conceito de trace. Sublinhe-se, em conformidade aos referenciais teóricos dessa pesquisa, que as comunidades jamais haviam estabelecido contato anterior entre si. Em outro eixo, o documentário compara três comunidades negras, uma em Salvador, outra no Recife e uma terceira em Alcântara, no Maranhão, no que se ressalta suas descontinuidades latentes. 


\section{Primeiras considerações}

O lugar resume o desafio colocado a noções que visam a dar conta das construções identitárias afroamericanas: as condições necessárias à relação entre a globalidade e a localidade, "telle qu' on puisse, sans défaire le lieu, sans diluer le lieu, 1'ouvrir" (GLISSANT, 1996, p. 30) ${ }^{14}$. Sob o signo da Relação, o lugar opera uma relação particular com a totalidade-mundo propondo, uma vez aceitos os termos, os domínios próprios à literatura em um contexto global:

Le poète a toujours revendiqué pour sa connaissance ce rapport à la "totalité-monde" qui seul autorise ses accents les plus innocents. Mais c'est seulement aujourd'hui que, la totalité-monde enfin réalisée concrètement et géographiquement, cette vision du monde, qui auparavant dans la littérature était "prophétique", peut se déployer ou s'exercer en pregnant pour objet véritablement ce qui n'était pas auparavant que sa visée. (Idem, p. 34)

O poeta sempre reivindicara, para seu conhecimento, sua relação com a "Totalidade-terra" que, por si mesma, autoriza seus sinais mais inocentes. Mas apenas hoje, com a Totalidade-terra enfim realizada, concreta e geograficamente, esta visão do mundo que, outrora, na literatura, era 'profética', apenas hoje pode se desdobrar ou se exercer tomando por objeto, verdadeiramente, o que antes nada mais era que sua visada. (tradução minha)

A relação entre a literatura e o lugar pode ser proposta não nos termos de uma clivagem global-local como propusera René Ménil, em rodapé de Le discours antillais ${ }^{15}$, e não exatamente nos termos de uma literatura na

Sublinhe-se, em conformidade aos referenciais teóricos dessa pesquisa, que as referidas descontinuidades demonstram o quanto o estudo da diáspora negra no Brasil exige a percepção mínima da heterogeneidade das crioulizações nas culturas afrobrasileiras: é preciso admitir que ser negro em Salvador é muito diferente de sê-lo no Recife que, por seu turno, é completamente diferente de sê-lo no Maranhão (dentro do qual, especificamente, ser negro na ilha é completamente diferente de sê-lo no continente).

14 Ante um problema colocado em bases semelhantes, Walter enumera uma lista de conceitos contemporâneos, atualmente em uso por parte de pesquisadores e ensaístas americanos, para a compreensão dos problemas identitários americanos em perspectiva global: "em conseqüência, o discurso crítico redescobriu a lógica das zonas de contato, espaços fronteiriços, limen, entrelugar, sincretismo, hibridismo, mestiçagem, crioulização e transculturação para explicar os fluxos disjuntivos e conjuntivos de transferências culturais e seus resultados: novas formas práticas culturais fractais entre fronteiras permeáveis" (2008, p. 37-38).

15 Constata-se, no argumento de Ménil em questão, na clivagem estabelecida entre o universal e o local, uma recorrência de metafísica da presença, em que à literatura dita local, definida por ausência de 
qual o escritor afrocaribenho seria "como o novo agrimensor de um espaço a ser construído" como propusera Daniel-Henri Pageaux (2011, p. 154) mas propor uma literatura capaz de, em uma implicação bicondicional, remeter o lugar do qual enuncia à totalidade-mundo. Glissant conceitua a presente bicondicionalidade como uma poética da totalidade-mundo, $o$ que permite constatar que, dela, torna-se possível remeter ao lugar e ao mundo, ao passo que uma poética do lugar remeteria apenas a si mesma, redundando em formações identitárias radiculares, ensimesmadas. $\mathrm{O}$ problema atinente a uma poética reduzida ao lugar consiste no elemento próprio à natureza dos essencialismos: uma definição do Ser por exclusão, onde definir consiste, antes de tudo, em determinar quem (ou o que) não é. Contrariamente, uma poética da totalidade-mundo, em sua ligação bilateral entre o local e o global, diz o lugar, visando a estabelecer as possibilidades a um discurso entre o lugar e outros lugares possíveis, de modo rizomático, em coerência à imprevisibilidade no cerne dos processos de crioulização das culturas e, em suas últimas consequências, o risco não negligenciável da inexequibilidade do projeto em escala global.

No tocante à leitura de Adèle et la pacotilleuse, convém destacar dois problemas dedutíveis do debate em questão. Como condição necessária à Relação, são necessárias ao menos duas identidades "maîtresses d'ellesmêmes", o que implica a predisposição à troca, em que ambas as identidades se transformam. Na medida em que se investiga a viabilidade da troca entre as identidades de Céline e de Adèle é necessário, para estabelecer a Relação, indagar em que medida ambas se disponibilizam às trocas. Em dado momento do capítulo "Langues et langages", Glissant (1996) distingue dois tipos de pensamento: qualifica um deles de pensamento continental, postulando sua dificuldade em compreender "le non-systéme généralisé des cultures du monde"; e outro de pensamento arquipélico que, embora mais intuitivo e frágil, se mostra mais apta a compreender o caos-mundo e a imprevisibilidade. Ante tal distinção, cabe a questão acerca do quanto Adèle se mostraria disposta a arquipelizar no contato com Céline e, dada a bicondicionalidade do princípio, em que medida Céline se mostraria disposta a enfrentar a opacidade do pensamento continental de Adèle. $\mathrm{O}$ desafio encontra sua forma exemplar na análise de Céline sobre os conceitos de exílio dela e de Adèle: para esta, o exílio é vivido como provação pois, fora do lugar-Paris, "la vie est dénuée de sens" (p. 77); ao passo que, para Céline, o exílio como força criadora, como condição, como destino, encontra uma

universalidade, restaria abandonar o décor do que é particularmente específico, despindo-se em nome da aquisição de uma condição universal na qual se viabilizaria seu valor estético. 
dificuldade significativa quando a pacotilleuse percebe a França, sobretudo as ilhas de Jersey e Guernesey nas quais Hugo esteve exilado, "îles dont j'ai quelque peine à concevoir les contours tant pour moi l'Europe est synonyme de continent" (p. 77). Não obstante, ambas experimentam a compreensão do lugar, enunciando dele à totalidade-mundo dentro de seus limites próprios: a razão para Adèle, a dificuldade de pensar a França arquipelicamente para Céline. Enquanto a pacotilleuse faz duas viagens à França, Adèle elabora um discurso de análise da peça Bug-Jargal, de Victor Hugo (CONFIANT, 2007, p. 57-60) que representa, simultaneamente, um esforço de compreensão do lugar e de compreensão do próprio pai (ao qual até então subsumira sua própria identidade):

Me suis-tu, Céline Alvarez? À la vérité, mon père était dans l'erreur complète. Au Canada, les Nègres se nommaient Georges, Marck ou Vincent comme tout le monde tandis qu'ici, à la Barbade, j'ai remarqué qu'ils affectionnent les prénoms bibliques comme Abraham ou Ismaël. Aucun qui arbore un nom de la trempe de Bug-Jargal! (CONFIANT, 2007, p. 60-61)

Dentro dos limites possíveis a sua desrazão (fora internada na Casa de Saúde, no capítulo 8), Adèle experimenta a compreensão do lugar-arquipélago mediante duas afirmações fortes no contexto da trama. Na primeira, assevera que o pai, ao redigir Bug-Jargal a partir das circunstâncias históricas, e malgrado sua apreciação do tema da independência haitiana, não compreendera os negros americanos, talvez fetichizando um lugar americano onde jamais estivera. $\mathrm{O}$ esforço de compreensão de Adèle inclui não apenas a observação dos sujeitos negros americanos que "se nommaient Georges, Marck ou Vincent comme tout le monde" como a atenção a especificidades de certas ilhas, como no caso de Barbados (onde ela e Céline se encontraram pela primeira vez, na página 17) em que se prefere "prénoms bibliques comme Abraham ou Ismaël”. Na segunda, Adèle culmina seu solilóquio recorrendo a estratégias narrativas herdadas de Céline ("Me suis-tu, Céline Alvarez?") para ressaltar o quanto a pacotilleuse, por ser a única a não tratá-la como louca, fora a única que verdadeiramente a compreendeu:

Et toi, Négresse, tu es devenue presque une mère pour moi. Tu es la première à m'écouter sans me juger. Tu ne me traites point de folle à lier lorsque je te parle de l'amour que j'éprouve pour Albert Pinson. Tu me comprends, toi qui n'a jamais mangé dans une assiette en porcelane ni dansé le menuet. Toi, Céline Alvarez Bàà! Et comme Bug-Jargal adressant à D'Auverney, le 
colon blanc, cette requête sublime: "Puis-je t'appeler frère?", je te reclame désormais pour mère. Oui... (Idem, p. 61)

Visto a partir do pensamento ensaístico caribenho, Adèle et la pacotilleuse, para além de uma história de amor de uma jovem louca, consiste em um exercício literário de compreensão da alteridade.

\section{BIBLIOGRAFIA}

ALVES, Alcione Corrêa. 'Mon Nom, je l'habite tout entier: francofonia, littérature-monde e seus lugares de enunciação. 2012. $208 \mathrm{f}$. Tese (Doutorado em Letras) - Universidade Federal do Rio Grande do Sul. Instituto de Letras. Programa de Pós-Graduação em Letras, Porto Alegre, 2012.

BERND, Zilá. Por uma estética dos vestígios memoriais: releitura da literatura contemporânea das Américas a partir dos rastros. Belo Horizonte: Fino Traço, 2013.

BRATHWAITE, Edward Kamau. Islands. In: The Arrivants: A New World Trilogy (Rights of Passage, Masks, Islands). New York: Oxford University Press, 1973.

CARPENTIER, Alejo. El reino de este mundo. In: Obras completas de Alejo Carpentier. Volumen 2: El reino de este mundo; Los pasos perdidos. Buenos Aires: Siglo Veintiuno Editores, s.d., p. 13-119.

CÉSAIRE, Aimé. Une tempête. Paris: Éditions du Seuil, 2008. CHAMOISEAU, Patrick. Texaco. Paris: Gallimard, 1992.

CONDÉ, Maryse. Moi, Tituba sorcière.... Paris: Gallimard, 1986.

CONFIANT, Raphaël. Adèle et la pacotilleuse. Paris: Mercure de France, 2007 (Folio, 4492)

. La panse du chacal. Paris: Gallimard, 2006 (Folio, 4210)

CULLER, Jonathan. Writing and logocentrism. In: On deconstruction: theory and criticism after structuralism. Ithaca, New York: Cornell UniversityPress, $4^{\text {th }}$ printing, 1985. p. 89-110

DERRIDA, Jacques. L'écriture et la différence. Paris: Éditions du Seuil, 1967 (Collection “Tel quel”)

GAGLIETTI, Mauro; BARBOSA, Márcia Helena Saldanha. A questão da hibridação cultural em Nestor García Canclini. VII Congresso Brasileiro de Ciências da Comunicação da Região Sul. Passo Fundo, 2007. Disponível em <http://www.intercom.org.br/papers/regionais/sul2007/resumos/ R0585-1.pdf $>$. Acesso em 04 mar 2012. 
GIN, Pascal. Entre ambivalence et réflexivité: la mobilité culturelle et sa mobilisation littéraire dans l'écriture de la migration. Interfaces Brasil/Canadá: Revista da ABECAN, nº, p.73-89, 2008. GLISSANT, Édouard. Introduction à une poetique du divers. Paris: Gallimard, 1996.

. Le discour antillais. Paris: Gallimard, 1997.

KANOR, Fabienne. Humus. Paris: Gallimard, 2007 (Continents noirs) LE CLÉZIO, Jean Marie Gustave. L'Africain. Paris: Gallimard, 2010. Collection Folio, 4250)

PAGEAUX, Daniel-Henri. Espaços do imaginário americano e literatura mundial: região, nação, continente. In: Musas na encruzilhada: ensaios de Literatura Comparada. Marcelo Marinho, Denise Almeida Silva, Rosani Ketzer Umbach (orgs.). Prefácio de Eduardo de Faria Coutinho. Traduzido por Eurídice Figueiredo. Frederico Westphalen: URI; São Paulo: Hucitec; Santa Maria: UFSM, 2011. p. 149-164.

PLATÃO. Teeteto. Tradução de Adriana Manuela Nogueira e Marcelo Boeri. Prefácio de José Trindade Santos. Lisboa: Fundação Calouste Gulbenkian, 3a. Edição, 2010.

REIS, Maria Firmina dos. Úrsula. Posfácio de Eduardo de Assis Duarte. Florianópolis: Mulheres, 2004.

RICEUR, Paul. La mémoire saisie par l'histoire. Revista de Letras, São Paulo, v. 46, n. 1, 2006, p. 245-258.

SAID, Edward. Cultura e imperialismo. Tradução de Denise Bottman. São Paulo: Companhia das Letras, 1995.

SEIDEL, Roberto H. Apresentação. In: Afro-América: diálogos literários na diáspora negra das Américas. Recife: Bagaço, p. 9-13, 2009. (Coleção Letras) WALTER, Roland. Mobilidade cultural: o (não-)lugar na encruzilhada transnacional e transcultural. Interfaces Brasil/Canadá: Revista da ABECAN, nº, p.37-56, 2008.

- Tecendo identidade, tecendo cultura: os fios da memória na literatura afrodescendente das Américas. In: FERREIRA, Elio; MENDES, Algemira de Macedo (orgs). Literatura afrodescendente: memória e construção de identidades. São Paulo: Quilombhoje, 2011, p. 159-172.

Recebido em: 01/07/2014. Aceito em: 13/07/2014. 